\title{
Gold-catalyzed ethylene cyclopropanation
}

\author{
Silvia G. Rull, Andrea Olmos* and Pedro J. Pérez*
}

\section{Full Research Paper}

\section{Address:}

Laboratorio de Catálisis Homogénea, Unidad Asociada al CSIC, CIQSO-Centro de Investigación en Química Sostenible and Departamento de Química, Universidad de Huelva, Campus de EI Carmen 21007 Huelva, Spain

\section{Email:}

Andrea Olmos* - andrea.olmos@dqcm.uhu.es; Pedro J. Pérez* perez@dqcm.uhu.es

* Corresponding author

Keywords:

carbene transfer; cyclopropane; cyclopropylcarboxylate; ethylene cyclopropanation; ethyl diazoacetate; gold catalysis
Beilstein J. Org. Chem. 2019, 15, 67-71.

doi:10.3762/bjoc. 15.7

Received: 17 October 2018

Accepted: 11 December 2018

Published: 07 January 2019

This article is part of the thematic issue "Cyclopropanes and cyclopropenes: synthesis and applications".

Guest Editor: M. Tortosa

(C) 2019 Rull et al.; licensee Beilstein-Institut. License and terms: see end of document.

\section{Abstract}

Ethylene can be directly converted into ethyl 1-cyclopropylcarboxylate upon reaction with ethyl diazoacetate $\left(\mathrm{N}_{2} \mathrm{CHCO} \mathrm{E}_{2} \mathrm{Et}, \mathrm{EDA}\right)$ in the presence of catalytic amounts of $\operatorname{IPrAuCl} / \mathrm{NaBAr}^{\mathrm{F}}{ }_{4}\left(\mathrm{IPr}=1,3\right.$-bis(2,6-diisopropylphenyl)imidazole-2-ylidene; $\mathrm{BAr}^{\mathrm{F}}{ }_{4}=$ tetrakis(3,5-bis(trifluoromethyl)phenyl)borate).

\section{Introduction}

Nowadays the olefin cyclopropanation through metal-catalyzed carbene transfer starting from diazo compounds to give olefins constitutes a well-developed tool (Scheme 1a), with an exquisite control of chemo-, enantio- and/or diastereoselectivity being achieved $[1,2]$. Previous developments have involved a large number of $\mathrm{C}=\mathrm{C}$-containing substrates but, to date, the methodology has not been yet employed with the simplest olefin, ethylene, for synthetic purposes [3]. Since diazo compounds bearing a carboxylate substituent are the most commonly employed carbene precursors toward olefin cyclopropanation, their use with ethylene leads to cyclopropane (Scheme 1b). De Bruin and co-workers have described [4] such product in a minor, secondary reaction (yields $<12 \%$ ) while studying the copolymerization of ethylene and ethyl diazoacetate with rhodium-based catalysts (Scheme 2a).

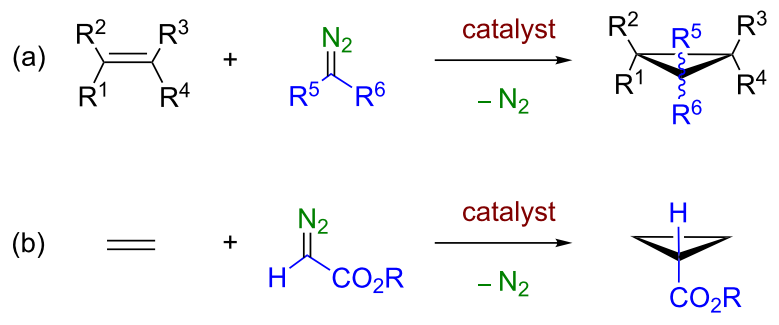

Scheme 1: (a) General metal-catalyzed olefin cyclopropanation reaction with diazo compounds. (b) The ethylene cyclopropanation with diazoacetates leads to cyclopropanecarboxylates.

Ethyl cyclopropanecarboxylate has been prepared in several ways, alternative to the direct carbene addition to ethylene (Scheme 2b): ring contraction of 2-halocyclobutanone [5], 


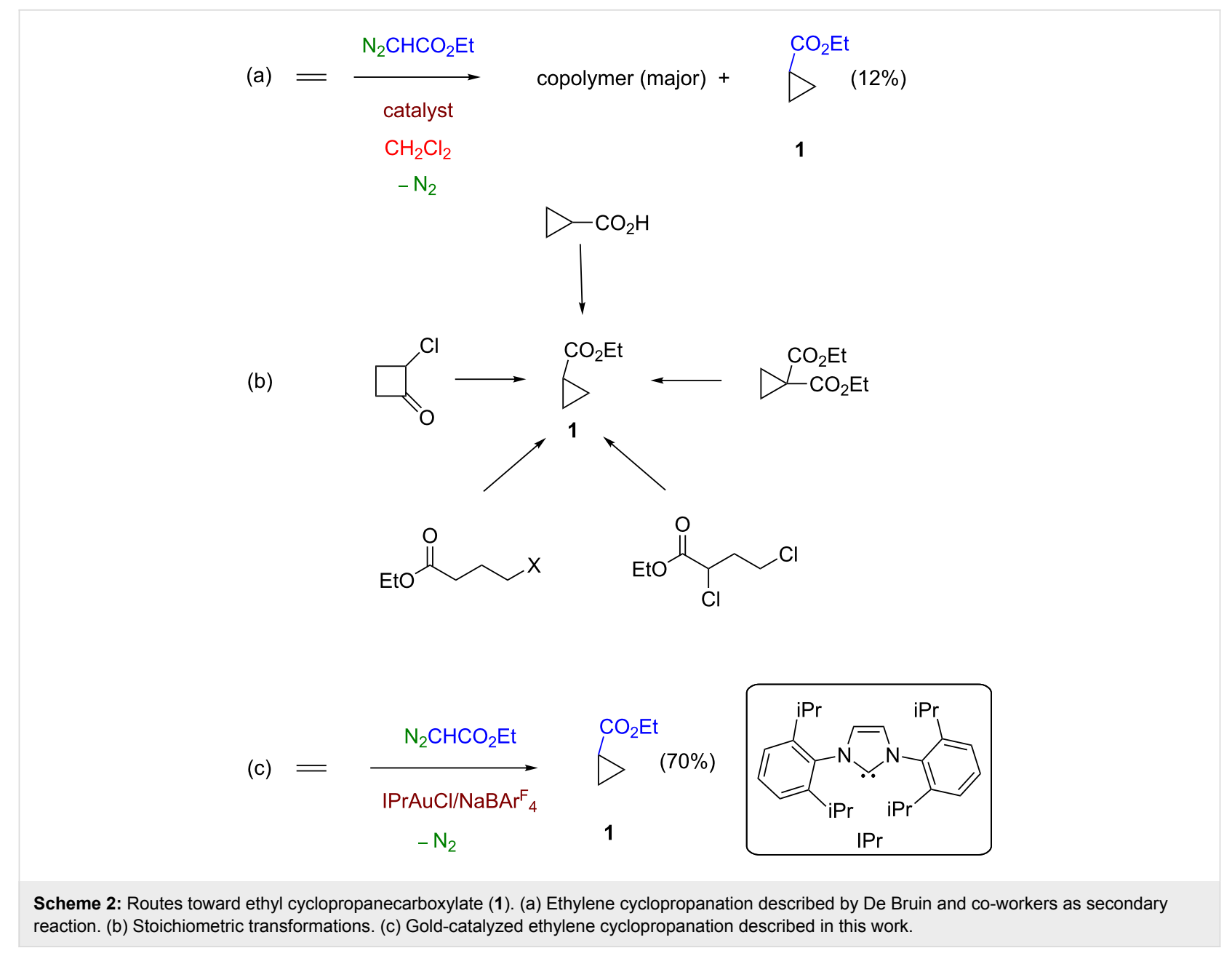

cyclization of alkyl 4-halobutanoates [6], electroreductive dehalogenation [7] and decarboxylation of diethyl 1,1-cyclopropyldicarboxylate [8]. Other methods include the transesterification of other alkyl cyclopropanecarboxylates [9] and the esterification with ethanol of the cyclopropanecarboxylic acid [10]. This product finds applications as lubricant additives [11], alkylating reagent in the Friedel-Crafts synthesis of indanones [12] or as synthon toward the introduction of cyclopropyl moieties in compounds with medicinal or biological interest $[13,14]$.

In view of the lack of examples of direct conversions of ethylene into cyclopropanecarboxylates, and given our experience with group 11 metal-based catalysts for carbene-transfer reactions from diazoacetates $[15,16]$, we have investigated this transformation and found that the gold complex IPrAuCl (IPr = 1,3-bis(2,6-diisopropylphenyl)imidazole-2-ylidene) along with one equivalent of $\mathrm{NaBAr}_{4}{ }_{4}\left(\mathrm{BAr}^{\mathrm{F}}{ }_{4}=\right.$ tetrakis(3,5-bis(trifluoromethyl)phenyl)borate) catalyzes the ethylene cyclopropanation with ethyl diazoacetate as the carbene precursor, under mild conditions, with moderate yields (ca. 70\%, EDA-based).

\section{Results and Discussion}

Diazo compounds $\mathrm{N}_{2}=$ CRR' usually react with metal complexes of groups 8-11 with formation of electrophilic metal-carbene intermediates $\mathrm{L}_{n} \mathrm{M}=\mathrm{CRR}$ ' [1,2] that further react with nucleophiles such as olefins en route to cyclopropanes. However, these intermediates can also react with another molecule of the diazo reagent promoting the formation of olefins $R R$ ' $C=C R R$ ' [17]. This side reaction frequently is avoided upon maintaining a low diazo compound/catalyst ratio, employing slow addition devices to incorporate a solution of the diazo reagent into the reaction mixture containing the olefin and the catalyst. Unfortunately, the use of ethylene as the olefin requires a pressure vessel and thus the diazo reagent must be added in one portion before pressurizing the system. This fact constitutes the main drawback when working with this alkene, and a highly chemoselective catalyst toward cyclopropanation over carbene dimerization is needed to enhance the former transformation.

In a first array of experiments, we tested several group 11 metal-based catalysts that have been described in our group for 
the catalytic transfer of the $\mathrm{CHCO}_{2}$ Et group from ethyl diazoacetate $\left(\mathrm{N}_{2}=\mathrm{CHCO}_{2} \mathrm{Et}, \mathrm{EDA}\right)$, as well as a rhodium-based catalyst. The experimental procedure started upon placing the catalyst $(0.02 \mathrm{mmol})$ into a Fischer-Porter vessel and addition of an EDA solution in $10 \mathrm{~mL}$ of dichloromethane via cannula under ethylene atmosphere, and then it was pressurized to 8 bar with the same gas. The mixture was stirred for $14 \mathrm{~h}$ and then investigated by GC (see the experimental section). The results are collected in Table 1 . The complex $\mathrm{Tp}^{\mathrm{Ms}} \mathrm{Cu}(\mathrm{thf})$, previously described as an excellent catalyst for olefin cyclopropanation [18], led to negative results, since only the olefins 2 (mixtures of diethyl fumarate and maleate) were detected at the end of the reaction. The second copper-based catalyst tested $\mathrm{Tp}{ }^{(\mathrm{CF} 3) 2, \mathrm{Br}} \mathrm{Cu}$ (thf) [19] gave some of the desired product 1 (Table 1, entry 2), albeit in low yield (15\%). Olefins 2 were also formed, although mass balance was not verified by GC studies. When the crude was analyzed by NMR, broad signals characteristic of polymeric materials were observed. Given that our goal was the development of a catalytic route for cyclopropane $\mathbf{1}$, we have not invested efforts in the characterization of such materials.

The silver complex $\mathrm{Tp}^{(\mathrm{CF} 3) 2, \mathrm{Br}} \mathrm{Ag}(\mathrm{thf})$ [19] (Table 1, entry 3) was not effective toward the aforementioned target, since only $5 \%$ of 1 was formed. In this case, the product derived from the insertion of the carbene $\mathrm{CHCO}_{2}$ Et group into the $\mathrm{C}-\mathrm{Cl}$ of the solvent was the major one, accordingly with previous work from this and other laboratories using silver-based catalysts
[20,21]. Therefore, we moved onto gold-based catalysts that had already been validated for EDA decomposition and carbene-transfer reactions [22,23]. Neutral IPrAuCl was not effective (Table 1, entry 4), assessing the need of a cationic, halide-free gold species toward that end. The choice of the halide scavenger is not innocent: on the other hand, it is key for the success of this search. Thus, addition of one equiv of AgOTf with respect to the gold complex resulted in low consumption of EDA, and minor amounts of 1, olefins 2 and cyclopropane $\mathbf{3}$ derived from carbene addition to $\mathbf{2}$ were detected. The use of $\mathrm{AgSbF}_{6}$ led to different results: the yield into desired 1 increased up to $25 \%$ but the functionalization of the solvent (4) constituted the main transformation. This is probably the effect of the silver in the reaction medium, since simple silver salts promote such reaction. The use of $\mathrm{NaBAr}_{4}{ }_{4}$ delivered ethyl cyclopropanecarboxylate (1) in $62 \%$ yield, with only $2 \%$ of olefins 2 as byproducts, the remaining $36 \%$ of initial EDA appearing unreacted at the end of the $14 \mathrm{~h}$ period. When the dirhodium complex $\mathrm{Rh}_{2}\left(\mathrm{CF}_{3} \mathrm{COO}\right)_{4}$ was submitted to the same experimental conditions, compound $\mathbf{1}$ was detected in $41 \%$ yield, along with $14 \%$ of olefins 2 . Again, the analysis of the crude mixture through NMR revealed the presence of polymeric material.

Once the $\mathrm{IPrAuCl} / \mathrm{NaBAr}^{\mathrm{F}}{ }_{4}$ was identified as the best choice toward the catalytic formation of $\mathbf{1}$, several reaction conditions were explored. As shown in Table 2, and plotted in Figure 1, four experiments carried out at 1,2, 4 and 8 bar of ethylene

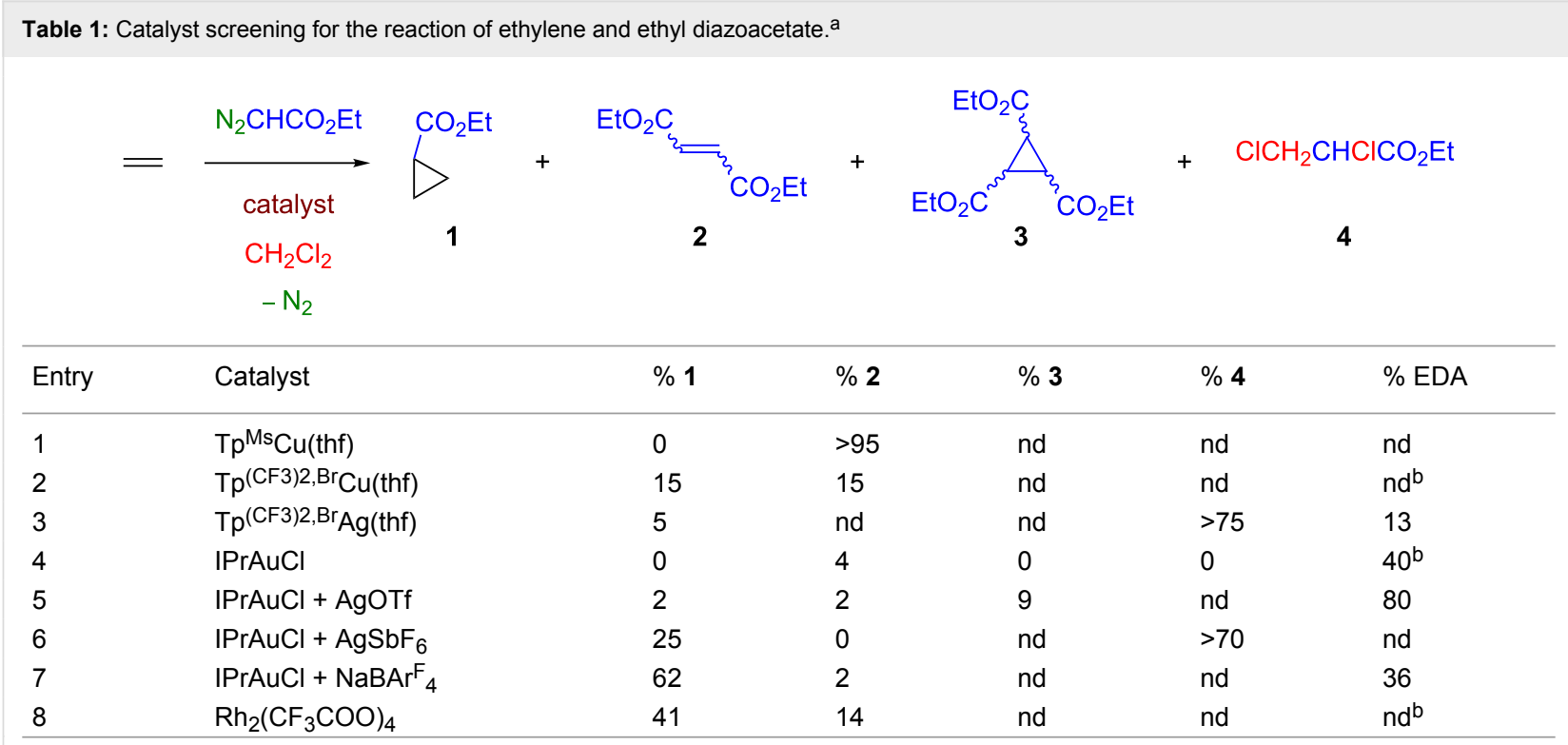

aReaction carried out with $0.02 \mathrm{mmol}$ of catalyst, $0.2 \mathrm{mmol}$ of EDA except with the rhodium catalyst, which was run with $0.4 \mathrm{mmol}$ of EDA. Ethylene pressure $=8$ bar. Solvent: $10 \mathrm{~mL}$ of dichloromethane. Room temperature. Product determination and quantification by GC with calibration curves, yields based on initial EDA. nd = not detected. ${ }^{b} \mathrm{NMR}$ studies show broad signals characteristic of polymeric materials accounting for $100 \%$ of initial EDA. 


\begin{tabular}{|c|c|c|c|c|c|c|}
\hline Entry & $\mathrm{P}\left(\mathrm{C}_{2} \mathrm{H}_{4}\right)$ (bar) & $\mathrm{V}\left(\mathrm{CH}_{2} \mathrm{Cl}_{2}\right)(\mathrm{mL})$ & $\% 1$ & $\% 2$ & $\% 3$ & $\%$ EDA \\
\hline 1 & 1 & 5 & 5 & $>90$ & nd & nd \\
\hline 2 & 2 & 5 & 39 & 2 & 35 & 12 \\
\hline 3 & 4 & 5 & 66 & 0 & 33 & nd \\
\hline 4 & 8 & 5 & 73 & 0 & 15 & $n d^{b}$ \\
\hline $5^{c}$ & 8 & 5 & 70 & 0 & 0 & $n d^{b}$ \\
\hline 6 & 8 & 10 & 62 & 2 & 0 & 36 \\
\hline
\end{tabular}

${ }^{a}$ Conditions and product numbering as described in Table 1. nd $=$ not detected. ${ }^{b}$ NMR studies show broad signals characteristic of polymeric materials accounting for $100 \%$ of initial EDA. 'Reaction performed at $40{ }^{\circ} \mathrm{C}$.

(Table 2, entries 1-4) revealed that the latter was the optimal value. This is clearly the effect of the need of a high concentration of the olefin in the reaction mixture, which is proportional to the partial pressure above the solution. Also, the use of a 5 $\mathrm{mL}$ volume of the solvent instead of $10 \mathrm{~mL}$ not only allowed to increase the yield up to $73 \%$ but also to induce complete consumption of ethyl diazoacetate. The effect of the temperature when moving from ambient (Table 2, entry 4 ) to $40{ }^{\circ} \mathrm{C}$ (Table 2, entry 5) was negligible, albeit in the former the cyclopropane 3 was observed. Again, some polymeric material was detected by NMR spectroscopy. It is worth mentioning that when diethyl diazomalonate or ethyl 2-phenyldiazoacetate were employed as the carbene precursor, no cyclopropanes were detected, only olefins formed from carbene dimerization as well as unreacted diazo compounds were identified at the end of the reaction.

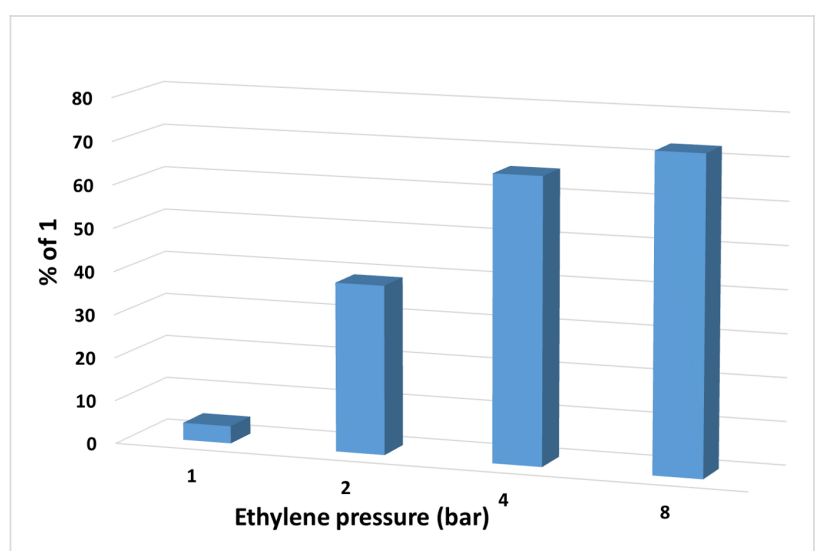

Figure 1: Effect of the pressure of ethylene on the yields of ethyl cyclopropanecarboxylate in the reaction of ethylene and EDA catalyzed by IPrAuCl/NaBArF ${ }_{4}$

\section{Conclusion}

We have found that the complex IPrAuCl in the presence of one equivalent of $\mathrm{NaBAr}_{4}{ }_{4}$ catalyzes the reaction of ethyl diazoacetate and ethylene, at room temperature, leading to ethyl cyclopropanecarboxylate with yields of ca. $70 \%$ (EDA-based). This is the first example of a direct cyclopropanation of ethylene by this methodology with significant conversions.

\section{Experimental General methods}

All preparations and manipulations were carried out under an oxygen-free nitrogen atmosphere using conventional Schlenk techniques. Solvents were rigorously dried prior to use. The substrates as well as compound $\mathbf{1}$ (for calibration curves) were purchased from Aldrich. The catalysts were prepared according to literature procedures, as well as $\mathrm{NaBAr}_{4}{ }_{4}$ [24]. NMR spectra were performed on Agilent $400 \mathrm{MR}$ and $500 \mathrm{DD} 2$. GC data were collected with an Agilent 7820A equipped with an FID detector and an Agilent HP-5 column of $30 \mathrm{~m} \times 320 \mu \mathrm{m} \times$ $0.25 \mu \mathrm{m}$. Method: $50{ }^{\circ} \mathrm{C} \times 1.5 \mathrm{~min}, 10{ }^{\circ} \mathrm{C} / \mathrm{min}, 250{ }^{\circ} \mathrm{C} \times$ $25 \mathrm{~min}$.

\section{Catalytic experiments}

Ethylene cyclopropanation with EDA. A $175 \mathrm{~mL}$ high pressure Fischer-Porter vessel equipped with a manometer and a valve was charged with $0.02 \mathrm{mmol}$ of $\operatorname{IPrAuCl}(24 \mathrm{mg})$ and $0.02 \mathrm{mmol}$ of $\mathrm{NaBAr}_{4} \mathrm{~F}_{4}(17 \mathrm{mg})$. The vessel was deoxygenated and filled with ethylene. A solution of $0.2 \mathrm{mmol}$ of EDA $(24 \mu \mathrm{L})$ in $5 \mathrm{~mL}$ anhydrous dichloromethane was added via cannula and the ethylene pressure was increased up to 8 bar. The reaction mixture was stirred for 14 hours and the pressure was released.

Reaction mixture analysis. The crude reaction mixture was diluted to $10 \mathrm{~mL}$ and directly analyzed by GC. The amounts of ethyl cyclopropanecarboxylate (1), EDA, diethyl maleate and diethyl fumarate (2) were determined using calibration curves ranging from $2 \mathrm{mM}$ to $20 \mathrm{mM}$, previously prepared using commercially available products. Retention times of products: 1, $5.78 \mathrm{~min}$; EDA, $5.90 \mathrm{~min}$; diethyl maleate, $10.73 \mathrm{~min}$; diethyl fumarate, $10.93 \mathrm{~min}$. To determine the quantity of triethyl 1,2,3cyclopropanetriscarboxylate (3) formed, the solution was evaporated and analyzed by NMR using $\mathrm{CDCl}_{3}$ as solvent and ethyl chloroacetate as internal standard. 


\section{Acknowledgements}

Support for this work was provided by the MINECO (CTQ2017-82893-C2-1-R and CTQ2015-73693-JIN).

\section{ORCID ${ }^{\circledR}$ iDs}

Andrea Olmos - https://orcid.org/0000-0002-1871-6395

Pedro J. Pérez - https://orcid.org/0000-0002-6899-4641

\section{References}

1. Lebel, H.; Marcoux, J.-F.; Molinaro, C.; Charette, A. B. Chem. Rev. 2003, 103, 977-1050. doi:10.1021/cr010007e

2. Caballero, A.; Prieto, A.; Díaz-Requejo, M. M.; Pérez, P. J. Eur. J. Inorg. Chem. 2009, 1137-1144. doi:10.1002/ejic.200800944

3. Rodríguez-García, C.; Oliva, A.; Ortuño, R. M.; Branchadell, V. J. Am. Chem. Soc. 2001, 123, 6157-6163. doi:10.1021/ja015676o Ethylene has been employed as the model alkene for some theoretical studies about the olefin cyclopropanation reaction using diazo reagents.

4. Franssen, N. M. G.; Reek, J. N. H.; de Bruin, B. Dalton Trans. 2013, 42, 9058-9068. doi:10.1039/c3dt32941k

5. Cyclobutanone. EROS Encyclopedia of Reagents for Organic Synthesis; American Cancer Society: USA, 2001.

6. von Seebach, M.; Kozhushkov, S. I.; Schill, H.; Frank, D.; Boese, R.; Benet-Buchholz, J.; Yufit, D. S.; de Meijere, A. Chem. - Eur. J. 2007, 13, 167-177. doi:10.1002/chem.200600799

7. Mitani, M.; Yamamoto, Y.; Koyama, K. J. Chem. Soc., Chem. Commun. 1983, 1446-1447. doi:10.1039/c39830001446

8. Hell, Z.; Tõke, L. Synth. Commun. 1996, 26, 2127-2133. doi:10.1080/00397919608003571

9. Mori, T.; Takamoto, M.; Wada, T.; Inoue, Y. Photochem. Photobiol. Sci. 2003, 2, 1187-1199. doi:10.1039/b305898k

10. Zhou, H.; Yang, J.; Ye, L.; Lin, H.; Yuan, Y. Green Chem. 2010, 12, 661-665. doi:10.1039/b921081d

11. Wang, Q. J.; Chung, Y.-W.; Johnson, B. A. Lubricant additives, lubricant compositions, and applications of same. WO Patent WO2016065175, Oct 23, 2014.

12. Pinnick, H. W.; Brown, S. P.; McLean, E. A.; Zoller, L. W., III. J. Org. Chem. 1981, 46, 3758-3760. doi:10.1021/jo00331a046

13. Cantley, A. M.; Welsch, M.; Ambesi-Impiombato, A.; Sanchez-Martín, M.; Kim, M.-Y.; Bauer, A.; Ferrando, A.; Stockwell, B. R. ACS Med. Chem. Lett. 2014, 5, 754-759. doi: $10.1021 / \mathrm{ml} 500044 \mathrm{~g}$

14. Qin, J.; Rao, A.; Chen, X.; Zhu, X.; Liu, Z.; Huang, X.; Degrado, S.; Huang, Y.; Xiao, D.; Aslanian, R.; Cheewatrakoolpong, B.; Zhang, H.; Greenfeder, S.; Farley, C.; Cook, J.; Kurowski, S.; Li, Q.; van Heek, M.; Chintala, M.; Wang, G.; Hsieh, Y.; Li, F.; Palani, A. ACS Med. Chem. Lett. 2011, 2, 171-176. doi:10.1021/ml100251u 15. Díaz-Requejo, M. M.; Pérez, P. J. J. Organomet. Chem. 2001, 617-618, 110-118. doi:10.1016/s0022-328x(00)00669-0

16. Caballero, A.; Díaz-Requejo, M. M.; Fructos, M. R.; Olmos, A.; Urbano, J.; Pérez, P. J. Dalton Trans. 2015, 44, 20295-20307. doi:10.1039/c5dt03450g

17. Rivilla, I.; Sameera, W. M. C.; Alvarez, E.; Díaz-Requejo, M. M.; Maseras, F.; Pérez, P. J. Dalton Trans. 2013, 42, 4132. doi:10.1039/c2dt32439c
18. Díaz-Requejo, M. M.; Caballero, A.; Belderraín, T. R.; Nicasio, M. C.; Trofimenko, S.; Pérez, P. J. J. Am. Chem. Soc. 2002, 124, 978-983. doi:10.1021/ja011895y

19. Gava, R.; Olmos, A.; Noverges, B.; Varea, T.; Álvarez, E.; Belderrain, T. R.; Caballero, A.; Asensio, G.; Pérez, P. J. ACS Catal. 2015, 5, 3726-3730. doi:10.1021/acscatal.5b00718

20. Dias, H. V. R.; Browning, R. G.; Polach, S. A.; Diyabalanage, H. V. K.; Lovely, C. J. J. Am. Chem. Soc. 2003, 125, 9270-9271. doi:10.1021/ja0348010

21. Urbano, J.; Braga, A. A. C.; Maseras, F.; Álvarez, E.; Díaz-Requejo, M. M.; Pérez, P. J. Organometallics 2009, 28 , 5968-5981. doi:10.1021/om9006888

22. Fructos, M. R.; Belderrain, T. R.; de Frémont, P.; Scott, N. M.; Nolan, S. P.; Díaz-Requejo, M. M.; Pérez, P. J. Angew. Chem., Int. Ed. 2005, 44, 5284-5288. doi:10.1002/anie.200501056

23. Fructos, M. R.; de Frémont, P.; Nolan, S. P.; Díaz-Requejo, M. M.; Pérez, P. J. Organometallics 2006, 25, 2237-2241. doi:10.1021/om0507474

24. Brookhart, M.; Grant, B.; Volpe, A. F. Organometallics 1992, 11, 3920-3922. doi:10.1021/om00059a071

\section{License and Terms}

This is an Open Access article under the terms of the Creative Commons Attribution License (http://creativecommons.org/licenses/by/4.0). Please note that the reuse, redistribution and reproduction in particular requires that the authors and source are credited.

The license is subject to the Beilstein Journal of Organic Chemistry terms and conditions: (https://www.beilstein-journals.org/bjoc)

The definitive version of this article is the electronic one which can be found at: doi:10.3762/bjoc. 15.7 